Vol. 5 (1), pp. 011-018, January, 2015

ISSN: 2276-7797; ICV: 5.98

Copyright @2015, the copyright of this article is retained by the author(s)

DOI Link: http://doi.org/10.15580/GJMS.2015.1.051114384

http://gjournals.org/GJMS

\title{
Traditional Medicine Treatment of Malaria in Onitsha, South East Nigeria
}

\author{
OGBUEHI I.H.* and EBONG 0.O.
}

Centre for Malaria Research and Phytomedicine, University of Port Harcourt, Nigeria.

Article No.: 051114384

Type: Research

DOI: 10.15580/GJMS.2015.1.051114384

Submitted: 11/05/2014

Accepted: 17/12/2014

Published: 30/01/2015

${ }^{*}$ Corresponding Author

Ogbuehi I.H.

E-mail: happyije@yahoo.com;

ijeoma.ogbuehi@uniport.edu.ng

\section{Keywords:}

Traditional Medical Practitioners, antimalarial, herbalists
A survey was conducted in the commercial city of Onitsha, South-east, Nigeria to ascertain the plants used in the treatment of malaria and the treatment practice in the herbal markets studied. Information was collected from herb sellers using semi-structured questionnaires, in-depth interviews and direct observation. Samples of all plants claimed to have antimalarial property were collected, identified and authenticated. A total of 481 respondents were interviewed. Of these, of which $49.7 \%$ were males and $50.3 \%$ females. Majority $(79.4 \%)$ of the respondents were herb-sellers while $20.6 \%$ were trainees. Eleven plant species used in the treatment of malaria were identified and information regarding the plants collected. The information collected includes their common names, parts used, methods of preparation, duration of treatment and other medicinal values, compiled. The frequency of encounter of the plants identified during the survey were as follows: Nauclea latifolia (22.6\%); Azadirachta indica (17.0\%); Sida acuta (11.8\%); Cymbopogon citratus (9.5\%); Alstonia boonei (7.6\%); Carica papaya (7.3\%); Morinda lucida (6.7\%); Ocimum gratissimum (6.4\%); Mangifera indica (4.2\%); Vernonia amygdalina (3.8\%); and Psidium guajava (3.1\%). Sixty percent of the concoction studied contained plant combination than single plants for the treatment of malaria. However, scientific validation of the traditional claims of antimalarial properties is imperative. This will contribute positively to the search for newer and more effective antimalarial drugs. 


\section{INTRODUCTION}

According to a survey, $90 \%$ of the world's cases of malaria occur in sub-Saharan Africa (Snow et al., 2005). The cost of malaria control and treatment drains African economies, slowing economic growth by about 1.3 per cent a year (UNICEF Report). In Nigeria, Malaria is a major public health problem, with an estimated 100 million malaria cases and over 300,000 deaths per year in Nigeria (Nigeria Malaria Fact Sheet, 2011). Monetary loss due to malaria in Nigeria is estimated to be about 132 billion naira in terms of treatment cost, prevention and loss of man-hours (FMOH, 2007).

According to the World Health Organization, the use of traditional medicine in various therapies is widespread, with as many as $80 \%$ of the world's indigenous population depending on it for their primary healthcare needs (WHO Report, 2008). Medicinal plants have been used in the treatment and prevention of malaria in various parts of the world.

Traditional medicine is the sum total of knowledge, skills and practices based on the theories, beliefs and experiences indigenous to different cultures that are used to maintain health, as well as to prevent, diagnose, improve or treat physical and mental illnesses ${ }^{13}$. Traditional medicine practice (TMP) is widely practiced in developing countries including Nigeria. It is a readily available, inexpensive method of therapy. Many people in our society prefer health care seeking with the traditional medicine practitioners because it is affordable and familiar with the culture, beliefs and practices of their culture (WHO, 2008).

However, one of the limitations of TMP is the non-documentation of the medicinal plant knowledge, given that it is mostly passed on orally by the elderly traditional herbal practitioners from one generation to the next. Hence, there is need to accurately identify, taxonomically classify and scientifically evaluate these traditional indigenous resources. This is the only way to create continued access into facts and skills of phytomedicine and make contributions to primary health care.

\section{MATERIALS AND METHODS}

Study area: The study was carried out among herb sellers and traditional medicine practitioners in three major markets (Ochanja, Ose and Main markets) in Onitsha. Onitsha is a commercial city and a river port on the eastern bank of the Niger River in Anambra State, Southeastern Nigeria. It is a densely populated city with an estimated population of 1,003,000 (2001 estimate) (Minahan, 2002). The city is home to the biggest market in the whole of Africa - the Onitsha Main Market as it is popularly known. Also it is the major center for trade between the coastal regions and the north, as well as between eastern and western Nigeria. The indigenous people of Onitsha are Igbos, but there are also a host of other settlers from different tribes such as Hausa, Yoruba and Efik.

Study population: There were a total number of 253 registered shop owners in the three herbal markets. The number of shops in the different herbal markets is as follows: Ochanja, 57; Ose market, 92 and Main market, 104. Each of the herbal markets has an association for the herb dealers headed by a Chairman and the Executive members. The information about the local names, use, parts of plants used, methods of preparation and administration of herbs were obtained from a total of 481 respondents drawn from the different markets.

Data collection method: Data was obtained through the use of semi-structured questionnaires and in-depth interviews. Also the treatment practices of the herbal practitioners were studied by means of direct observation by use of a local interpreter. Respondents included traditional medicine al practitioners, herbalists and herb sellers in the herbal markets.

Sample Size Determination: Information was obtained on the population strength of the shops. Sample size was determined using EPI - Info. The sample size obtained was rounded up to take care of attrition, nonresponse and for increasing the validity of the significant tests.

Instruments for Data Collection: Qualitative and quantitative instruments were adopted in collection of data.

\section{A. Qualitative Method}

1. In-depth Interviews (IDI): An in-depth interview guide was developed and used to design the questions to be asked. The interviews covered topics related to source of medicinal plant knowledge, duration of practice, medicinal plants used in the treatment of malaria, how the plants are sourced, mode of preparation, challenges in the course of their practice e.t.c. Where necessary the IDI's was conducted in the local language of the people and then translated into English.

2. Direct Observation: The researchers visited and directly observed the activities in the shops of willing respondents. Their traditional medicine practice and their pattern of health care provision were evaluated through observation.

3. Participant Observation: One of the herb sellers/practitioners was persuaded after being given monetary incentives to be understudied for a period of two weeks. A participant observation technique was used obtain information.

\section{B. Quantitative method}


Information gathered from the IDI was used in the development of interviewer-administered semi-structured questionnaires for the shop owners and their apprentices. The questionnaires contained both open ended and close ended questions. The questionnaires were divided into three sections. Section (1) extracted demographic information such as: age, sex, religion, local tribe, duration of practice, nationality, and the specialty. Section (2) is on knowledge of and usage of medicinal plants for a variety of ailments. The section consisted of questions like: how the respondent acquired knowledge of herbs, how diagnosis of patient's ailment is done, whether they refer cases and circumstances under which they refer cases, how decoctions are preserved, availability of the plants parts used, side effects, duration of treatment and how they determine dosage. Section (3) dealt with trainings, whether they have attended any training on traditional medicine practice and whether they will be willing to attend such, if given the opportunity to do so.

\section{Data Processing and Analysis:}

The data collected from the IDIs was recorded and summarized using the thematic approach, where important themes were highlighted and coded for analysis. Each questionnaire was also coded and the data and analyzed using statistical software.

\section{Informed consent:}

Permission was obtained from the Chairmen of the Herbal dealer's associations. Also, informed consent was obtained from all the participants after the purpose and nature of the study had been explained to them. In addition, information was collected from those learning the trade only after permission was granted them by their bosses.

\section{RESULTS}

\section{Demographic Characteristics:}

Of the 481 respondents, $13.9 \%$ of these respondents fall within age range, $10-30 \mathrm{yrs}, 31-50(36.7 \%)$ while $47.4 \%$ were 51 - 70 years; $49.7 \%$ were males and $50.3 \%$ females. Only $4.6 \%$ respondents had tertiary education; $45.3 \%$, secondary and $43.7 \%$ primary education, while $6.4 \%$ had no formal education.

The religions of the respondents were as follows; Christianity, 61.5\%; Traditional African Religion, $21.6 \%$; while Islamic tr $16.8 \%$ were Muslims.

The tribes of the respondents were as follows: $70.7 \%$ were Igbos; $20.4 \%$ were Yoruba; $6.0 \%$ were Hausas; $2.5 \%$ were Urhobo; and $0.4 \%$ Efik.

Majority of the respondents were actual herbsellers/shop owners, $79.4 \%$ while others, $20.6 \%$ were apprentices.

\section{Medicinal plant knowledge and Traditional practice:}

On the source of their medicinal plant knowledge: $49.8 \%$ said, by inheritance; $33.7 \%$, informal training; and $16.5 \%$ claimed divine inspiration.: They diagnose ailments by: physical examination, 40.4\%; patient's complaints, $36.9 \%$; divination $13.5 \%$ while $9.2 \%$ send patients for laboratory tests.

With regards to their duration of practice: $43 \%$ of them have practiced for more than 30 years; $51 \%$ of them have practiced for less than 30 years but more than 10 years; while $6 \%$ have practiced for fewer than 10 years.

On whether they refer cases, majority, 404 (84\%) were affirmative while $77(16 \%)$ does not refer cases. The circumstances under which they referred cases includes: adverse effects (41\%); treatment failure (37\%); other complications (22\%).

Majority of the respondents preserve the herbs by drying while the decoctions (herbal mixtures) are soaked in alcohol for extraction and preservation; however decoctions prepared by boiling can only last for days and cannot be refrigerated. They admitted having observed several side effects of the herbs in their patients; the commonest being, diarrhea (56\%), itching $(17 \%)$, worsening ailment $(11 \%)$, rashes $(9 \%)$ and dizziness $(7 \%)$. The respondents decried the challenges in their practice as follows: scarcity of plants, $17 \%$; storage facilities, $40 \%$; patient's unwillingness to pay bills, $11 \%$; all of the above, $32 \%$.

However, only $63 \%$ respondents willingly divulged methods of herbal preparation.

\section{Anti-malaria medicinal plants:}

Samples of all plants said to have antimalarial properties were taken. All samples were taken to the Plant Science and Biotechnology Department Herbarium in the University of Port Harcourt for proper identification.

The results showed that 11 plant species are in use for the treatment of malaria in the study area. Their botanical and local names respectively are as follows: Nauclea latifolia (Mburumuilu); Azadirachta indica (Dogonyaro); Cymbopogon citratus (Achara ehi); Morinda lucida (Ezeogu); Sida acuta (Udo); Alstonia boonei (Egbu) for fever; Ocimum gratissimum (Nchuanwu); Carica papaya (Poo-poo); Mangifera indica (Mangoro); Vernonia Amygdalina (Olugbu) and Psidium guajava (Gova).

Of the plants identified during the survey, their frequency of encounter were as follows: Nauclea latifolia (22.6\%); Azadirachta indica (17.0\%); Sida acuta (11.8\%); Cymbopogon citratus 9.5\%); Alstonia boonei (7.6\%); Carica papaya (7.3\%); Morinda lucida (6.7\%); Ocimum gratissimum (6.4\%); Mangifera indica (4.2\%); Vernonia Amygdalina (3.8\%); and Psidium guajava (3.1\%). A majority $(60 \%)$ of the concoction studied contained plant combination than single plants for the treatment of malaria. 
Table 1- List of Medicinal Plants Used For Malaria Therapy by Herb Sellers in a South Eastern Nigeria.

\begin{tabular}{|c|c|c|c|c|c|}
\hline Plant Botanical Name & Family Name & $\begin{array}{l}\text { Common /Local } \\
\text { Name }\end{array}$ & Parts used & Methods of Preparation & Other Medicinal Values \\
\hline Nauclea latifolia Sm & Rubiaceae & $\begin{array}{l}\text { African peach, } \\
\text { Mburumuilu }\end{array}$ & $\begin{array}{l}\text { Stem bark } \\
\text { and Roots }\end{array}$ & $\begin{array}{l}\text { a. Boil roots in water for } 2 \text { hours. } \\
\text { b. Soak overnight in water or alcohol, filter out the } \\
\text { filtrate and take half glass cup, three times daily. }\end{array}$ & Diabetes and Hepatitis \\
\hline $\begin{array}{l}\text { Azadirachta indica A. } \\
\text { Juss }\end{array}$ & Meliaceae & $\begin{array}{l}\text { Neem tree, } \\
\text { Dogonyaro }\end{array}$ & $\begin{array}{l}\text { Stem bark } \\
\text { and Leaves }\end{array}$ & $\begin{array}{l}\text { a. Boil leaves in water, allow to cool, then strain and } \\
\text { half glass cup, one in the morning and in the night. }\end{array}$ & $\begin{array}{l}\text { Hemorrhoids, Body Ache, and } \\
\text { Skin Infections }\end{array}$ \\
\hline $\begin{array}{l}\text { Cymbopogon citratus } \\
\text { (DC. Ex nees) Stapf }\end{array}$ & Poaceae & $\begin{array}{l}\text { Lemon grass, } \\
\text { Achara ehi }\end{array}$ & Leaves & $\begin{array}{l}\text { a. Boil dried grasses in a medium sized pot, half filled } \\
\text { with water, for } 30 \text { minutes. Allow to cool and strain } \\
\text { and full glass cup, one in the morning and in the } \\
\text { night. }\end{array}$ & Cough, Fever, Flu and Pneumonia \\
\hline Morinda lucida Benth & Rubiaceae & $\begin{array}{l}\text { Brimstone tree, } \\
\text { Ezeogu }\end{array}$ & $\begin{array}{l}\text { Leaves, } \\
\text { Stem Bark }\end{array}$ & $\begin{array}{l}\text { a. Boil leaves and stem bark for } 10 \text { minutes, strain and } \\
\text { serve half glass cup, twice daily. } \\
\text { b. Soak stem bark in ethanol for } 24 \text { hours, strain and } \\
\text { serve half glass cup, once daily. }\end{array}$ & Diabetes and Intestinal Worms \\
\hline Sida acuta Burn F. & Malvaceae & weed, & $\begin{array}{l}\text { Leaves, } \\
\text { Tender } \\
\text { stems }\end{array}$ & $\begin{array}{l}\text { a. Boil leaves and stem bark for } 30 \text { minutes, strain and } \\
\text { serve half glass cup, twice daily }\end{array}$ & Skin Diseases \\
\hline Ocimum gratissimum & Lamiaceae & $\begin{array}{l}\text { Scent } \quad \text { leaf, } \\
\text { Nchuanwu }\end{array}$ & Leaves & $\begin{array}{l}\text { a. Wash and squeeze two hand-ful of fresh or dried } \\
\text { leaves with water not more } 2 \text { big drinking cups. Take } \\
\text { the juice half cup, three times daily and discard the } \\
\text { remainder. }\end{array}$ & $\begin{array}{l}\text { Cleaning of a newborn's cord, } \\
\text { Epilepsy and Flu. }\end{array}$ \\
\hline $\begin{array}{l}\text { Alstonia boonei De } \\
\text { Wild }\end{array}$ & Apocynaceae & wood, & $\begin{array}{l}\text { Stem bark, } \\
\text { Root and } \\
\text { Leaves }\end{array}$ & $\begin{array}{l}\text { a. Boil all plant parts in water for } 30 \text { mins and allow } \\
\text { overnight. Then take half glass cup twice a day. } \\
\text { b. Soak roots and stem bark in alcohol over night and } \\
\text { strain. Then take half glass cup twice a day. }\end{array}$ & $\begin{array}{l}\text { Fever, Jaundice and Rheumatic } \\
\text { diseases }\end{array}$ \\
\hline Carica papaya L. & Caricaceae & Paw-paw & $\begin{array}{l}\text { Leaves and } \\
\text { seeds }\end{array}$ & $\begin{array}{l}\text { a. Boil fresh or dried matured leaves with grounded } \\
\text { seeds. Strain and take one glass cup, twice daily for } \\
3 \text { days. } \\
\text { b. Boil the leaves and inhale the steam under a } \\
\text { covered blanket. } \\
\text { c. Boil the leaves and allow for few minutes and bath } \\
\text { the water, warm. }\end{array}$ & Fever and Typhoid \\
\hline Mangifera indica L. & Anacardiaceae & Mango, Mangoro & Leaves & $\begin{array}{l}\text { a. Boil leaves in water, allow to cool, then strain and } \\
\text { half glass cup, one in the morning and in the night. }\end{array}$ & Jaundice and Asthma \\
\hline $\begin{array}{l}\text { Vernonia amygdalina } \\
\text { Del. }\end{array}$ & Asteraceae & $\begin{array}{l}\text { Bitter } \\
\text { Olugbu }\end{array}$ & Leaves & $\begin{array}{l}\text { W. Wash and squeeze leaf in a basin of water for } 5 \\
\text { minutes. Discard water, repeat process, strain and } \\
\text { drink half cup, twice daily. }\end{array}$ & Diabetes \\
\hline Psidium guajava L. & Myrtaceae & Guava, gova & Leaves & $\begin{array}{l}\text { a. Boil leaves in water, allow to cool, then strain and } \\
\text { half glass cup, one in the morning and in the night. }\end{array}$ & $\begin{array}{l}\text { Scurvy, Dressing wound and } \\
\text { Dental ache }\end{array}$ \\
\hline
\end{tabular}




\section{Botanical Names of the Constituent Family Names}

\section{of the Concoction}

a. Anthocleista nobilis G. Don

b. Nauclea latifolia Sm

a. Loganiaceae

b. Rubiaceae

c. Lecythidaceae

c. Napoleona imperialis P beauv

a. Acalypha wilkesiana Muell Arg

b. Carica papaya L

a. Euphorbiaceae

b. Caricaceae

c. Annonaceae

a. Rubiaceae

b. Apocynaceae

c. Apocynaceae

a. Anacardiaceae

b. Caricaceae

DC. Ex c. Poaceae

d. Meliaceae

a. Osisi kaguru

b. Ogbodo

c. Mangoro

d. Paw paw

\section{Local Names}

a. Okpokoro

b. Mburumuilu

c. Nnekeloche

a. Nchuanwu

b. Poo-poo

c. Dokita Igbo

\section{Plant parts used}

a. Root

b. Root

c. Stem bark, Root

a. Leaves

b. Leaves, seeds

c. Stem bark

\section{Medicinal Uses}

$\begin{array}{lll}\text { a. Mburumuilu } & \text { a. Root } & \text { a. Anti-malaria } \\ \text { b. Egbu } & \text { b. Root } & \text { b. Fever } \\ \text { c. Osi-igwe } & \text { c. Seeds, fruit rind } & \text { c. Mild anti-malaria }\end{array}$

a. Cleanses the system

b. Anti-malaria

c. Fever

a. Blood tonic, detoxifier

b. Anti-malaria

c. Mild anti-malaria, detoxifier

Anti-malaria

Osi-igw

C. Seeds, fruit rind $\mathrm{a}+\mathrm{b}+\mathrm{c}+\mathrm{d}=$

a. Cashuu a. Stem bark, Leaves

For anti-malaria steam bath.

b. Poo-poo

b. Leaves

c. Leaves

d. Dogonyaro d. Leaves
a. Solanaceae
b. Rubiaceae
c. Meliaceae
a. Solanum nigrum Lin
a. Anara ugumakpe
a. Leaves, whole fruits
a. Fever , Replenisher
b. Morinda lucida Benth
b. Ezeogu
b. Leaves, stem bark
b. Anti-malaria, Replenisher
chaya grandifoliolia
c. Oganwo
c. Stem Bark
c. Mild anti-malaria, fever

$\begin{array}{llll}\text { a. Strophantus hispidus } & \text { a. Osisi kaguru } & \text { Roots } \\ \text { b. Acioa barteria } & \text { b. Ogbodo } & \text { b. Roots } \\ \text { c. Magnifera indica } & \text { c. Mangoro } & \text { c. Leaves } \\ \text { d. Carica papaya } & \text { d. Paw paw } & \text { d. Leaves }\end{array}$


Plant family: Among the families, Rubiaceae provided the highest proportion (20\%) of anti-malarial plants used in the studied area.
Plant Parts used: The result shows that the plant part most commonly used are the leaves, roots and stem bark.

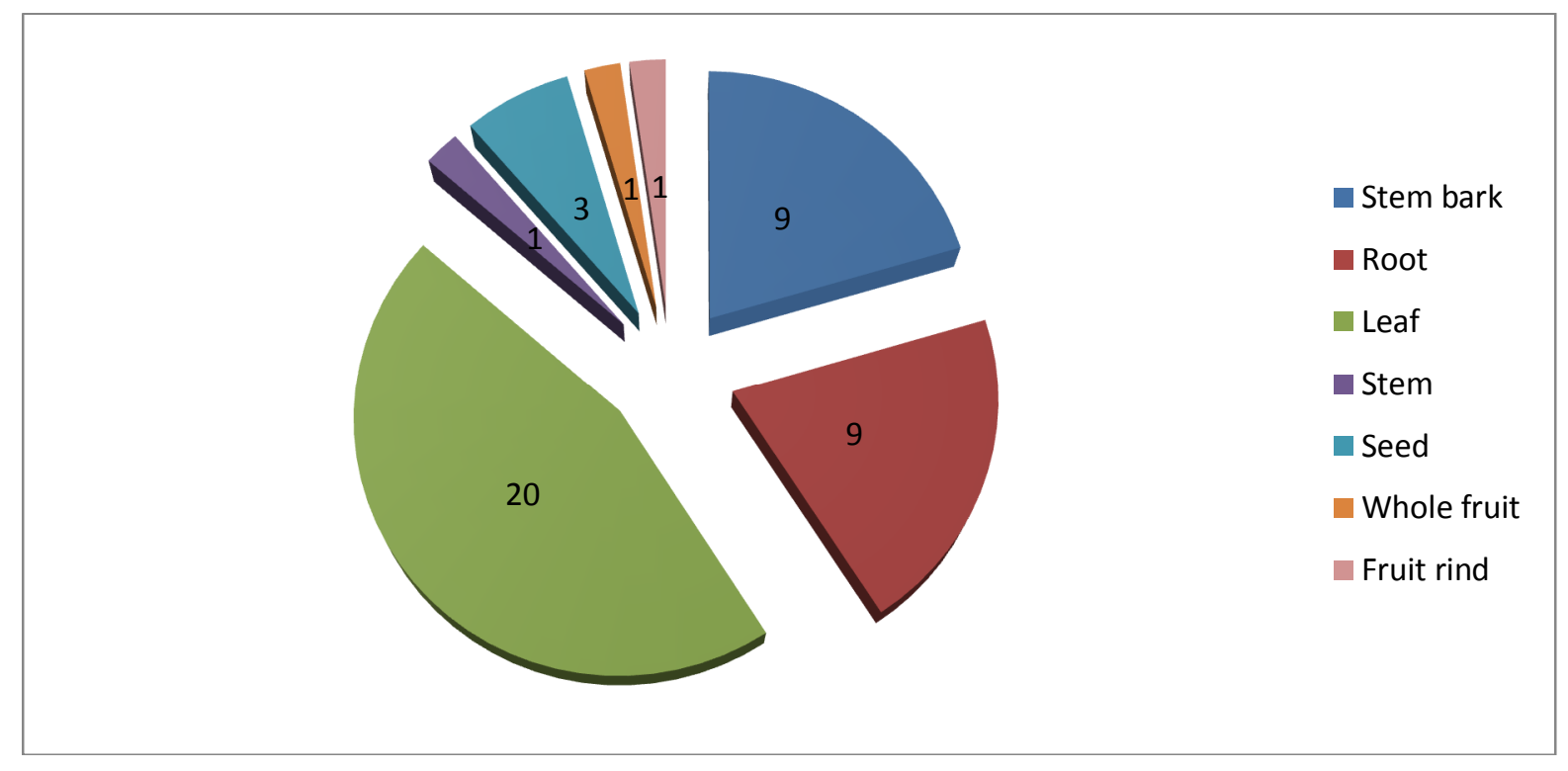

Fig 1: Showing the Distribution of Plant parts Used

\section{Herbal preparations and administration methods:}

Various methods of preparation and administration of the herbal remedies were recorded during the study. The commonest methods of preparation and administration of these anti-malarial remedies were either by soaking or boiling the plant parts in water or alcohol and subsequently sifting out the filtrate. The herbal medicine (usually a mixture) is then administering to the recipient in glass cup measures of varying sizes. Many respondents $(67 \%)$ indicated that alcohol is the most preferred solvent of extraction; however others preferred water $(24 \%)$ and carbonated drinks (9\%). It was observed that solvents other than alcohol is employed mostly when preparing medications for patients who abstain from alcohol due to personal, religious or health reasons.

Most of the herbs were to be taken orally, however in some instances, the herbs were boiled and allowed to cool, after which the patient was to drink and also bath with the filtrate. Other ways of administering the herb are as ointment, swallowed raw, or chewed, depending on the severity of the ailment. Based on information obtained, plant materials were either used fresh or air-dried, however most of the herbs used were in dried forms, they explained that it was necessary to dry plants in the dry season for use during the wet season.

We took note with keen interest that most of the medications sold for malarial therapy were plant combination with other plants or substances decoctions. These were locally referred to as 'AgboIba' meaning 'malaria concoction.' Table 3 shows that there were 6 of such herbal mixture, and 10 other plants that are used as adjuncts in the preparation of the concoctions and were said to be blood builders, detoxifiers, body cleansers, immune boosters e.t.c. The data indicated that the leaves, roots and bark of these plants were the most commonly used parts for anti-malarial treatment.

One of the respondents willingly allowed a member of the research team to observe her practice for one week by direct participant method. Thus, it was observed that the herbs (mostly leaves) used by the herbalist were from her farm while others (especially plant roots and stem barks) were supplied to her by dealers who operate from the interior villages. This respondent, when asked whether she will like to partner with orthodox practitioners to enhance her practice, answered "yes, our goals are the same - to achieve cures in the best possible way, so we are one in a sense, so we can work together and why not". Apart from treatment of the sickness in question, it was noticed that the herbalist took care to ensure the complete recuperation of the patient by administering herbs that are said to be blood tonic, energizers, vitamin-packed and immune boosters. Follow-up monitoring of her patients were also observed. Additional results from the direct and participant observation of the herbalists show that: 
- They all have specialty areas but all treat common illness such as malaria.

- Many of them refer patients to nearby medical laboratories before and after malaria therapy to confirm parasitemia and lend proof to the potency of their concoction.

- Many of them prescribe herbal mixtures for malaria therapy rather than single herbs.

- They render client-centered, personalized services.

- They sell herbs or offer medical services to an average of 8 'customers' per day.

However, the issue of cleanliness is a cause for concern in their practice. Generally, it can be said that good sanitary practices were not being upheld in the handling and preparation of the herbal drugs.

\section{DISCUSSION AND CONCLUSIONS}

Most of the herb sellers were middle aged and elderly women. A similar age range was obtained in a related survey (Ajaiyeoba et al. 2003.) The respondents were mainly lgbos followed by Yorubas with $61.5 \%$ of them practicing Christianity. Various ethnobotanical surveys have been conducted to identify plants indigenously used in the treatment of malaria (Odugbemi et al., 2007; Dike at al., 2010).

A greater proportion of the anti-malaria plants studied were of the Rubiaceae family, which is also the family where Cinchona plant (source of quinine) belongs. There are species, which were cited in this study, that are also known to be used as sources of anti-malarial remedies in other parts of Africa e.g. Azadirachta indica, Morinda lucida and Nauclea latifolia (Ayitey-Smith, 1989; Abbiw, 1990; Mshana et al., 2001; Njoroge and Bussmann, 2006; Iwu, 1993). Most of the plants identified in the study are consumed orally in the form of decoction. Plant species identified in the study were employed both singly and in combination with other anti-malarial plants; this may be due to the synergistic effect of these plants in the destruction of the plasmodium species or in the optimal management of the symptoms of malaria. Interestingly, many of the plants identified in this study have been studied scientifically. For example, Alstonia boonei has been shown to have significant antimalarial activity and currently, herbal formulations have been generated for such use (Majekodunmi et al., 2008).

Cymbopogon citratus, Morinda lucida, Azadirachta indica, Mormordica charantia, Alstonia boonei, and Anacardium occidentale were reported to have been singly employed in the treatment of malaria during this study. This may indicate that these eleven plants have high anti-malarial activity. Many other plants are used in combination because the sum total of their individual properties provides greater relief from symptoms or clears parasite more effectively than when used singly. However, none of the respondents provided any information on effort or actual standardization of these remedies. This represents the major drawback of traditional medicine (Asase et al., 2005)

Also, the list of plants for malaria treatment provided in this study is by no means exhaustive as some of the herb-sellers did not volunteer information and some that did, may not have proffered all the information in their arsenal, due to their believe in secrecy of their treatment formular. Some amongst the respondents that shared their knowledge did so only after receiving monetary incentives from the research team.

Thus, there is an urgent need to study these concoctions especially the polyherbal preparation since combination therapy is the current trend in the management of malaria in orthodox medicine. By means of standard in vitro and in vivo test, potentially active compounds could be identified and isolated for proper characterization.

Our experience shows that more respondents are willing to share their knowledge of medicinal plant with the scientific community once they were assured that it was for research purposes. Many people still trust and rely on the traditional healers for cures; hence it is imperative that they be incorporated into the nation's primary health care, given the wide acceptance of their practice.

This survey has documented various herbs and recipes of single and polyherbal combinations used in the treatment of malaria in Onitsha, Anambra state, South east, Nigeria. This publication has also provided a peep into the practice and attitude of herbalists in this part of the country.

\section{ACKNOWLEDGEMENT}

The authors gratefully acknowledge the technical assistance provided by the forestry department of the University of Port Harcourt. We also want to specifically thank Mrs Udoji Chinago who introduced the research team to her fellow herbsellers, thereby facilitating their willingness and cooperation. We are grateful to members of staff of the Herbarium Department of Plant Science and Biotechnology, University of Port Harcourt, Rivers State, Nigeria, in confirming the identity of some plants. Also, we appreciate the efforts of the Industrial Training students from Department of Plant Science and Biotechnology, University of Port Harcourt, attached to the Center for Malaria Research and Phytomedicine, UNIPORT, for their invaluable assistance during data collection.

\section{REFERENCES}


Snow R.W, Guerra C.A, Noor A.M, Myint H.Y and Hay S.I (2005). The global distribution of clinical episodes of Plasmodium falciparum malaria. Nature 2005, 434:214-217.

Malaria Fact Sheet: UNICEF (2011). http://www.unicef.org/health/files/health_africamalar ia.pdf

Nigeria Malaria Fact Sheet, (2011). http://photos.state.gov/libraries/nigeria/231771/Publi c/December-MalariaFactSheet2.pdf

Federal Ministry of Health (2007). National Frame work for monitoring and Evaluation of Malaria Control in Nigeria. FMOH, Abuja.

WHO Report (2008) - Fact Sheet - Medic CenterTraditional Medicine. http://www.who.int/mediacentre/factsheets/fs134/en /

World Health Organization - Traditional Medicine. (2008).

http://www.who.int/topics/traditional_medicine/en/

Minahan, J. (2002). Encyclopaedia of the Stateless Nations:762: S-Z. Greenwood Publishing Group.

Ajaiyeoba E.O, Onocha P.A, Nwozo S.O, Sama W. (2003). Antimicrobial and cytotoxicity evaluation of Buchholzia coriacea stem bark. Fitoterapia 74 (7-8): 706-709

Odugbemi T.O., Akinsulire O.R., Aibinu I.E and Fabeku O.P. (2007). Medicinal Plants Useful for Malaria Therapy in Okeigbo, Ondo State, Southwest Nigeria. Afr. J. Trad. CAM. 4 (2): 191 - 198

Dike I.P., Obembe O.O., Adebiyi E.F. (2012) Ethnobotanical survey for potential anti-malarial plants in south-western Nigeria. Journal of
Ethnopharmacology

http://dx.doi.org/10.1016/j.jep.2012.10.002

(2012),

Ayitey-Smith E., Addae-Mensah I. (1977). A preliminary pharmacological study Winnine: A piperine type of alkaloid from the roots of Piper guineense. W. Afr. J. Pharmacol. Drug Res. 4: 7-8.

Abbiw T. (1990). Study of Tropical shrubs and plant. J. Biogeorge. 23: 591-602

Mshana R.N., Abbiw D.K., Addae-Mensah I., Adjanouhoun E., Ahyi M.R.A., Ekpere J.A., EnowRock E.G., Gbile Z.O., Noamesi G.K., Odei M.A., Odunlami A., Oteng-Yeboah A.A., Sarpong K., Sofowora A., Tackie A.N. (2001). Traditional Medicine and Pharmacopoeia; Contribution to the Revision of Ethno botanical and Floristic Studies in Ghana. Science and Technology Press, CSIR.

Njoroge G.N., Bussmann R.W. (2006). Diversity and utilization of antimalarial ethnophytotherapeutic Remedies among the Kikuyus (Central Kenya). J. Ethnobiol. Ethnomedicine 2: 8

Iwu, M.M., Igboko O.A., Okunji C.O. and Tempesta M.S. (1990). Antidiabetic and aldose reductase activities of biflavanones of Garcinia kola. J. Pharm. Pharmacol., 42: 290-292.

Majekodunmi S. O., Odeku O. A., Adegoke O. A. (2008). Formulation of the extract of the stem bark of Alstonia boonei as tablet dosage form. Tropl J. of Pharm. Res, 7 (1): 870-880

Asase A., Oteng-Yeboah A.A., Odamitten G.T., Simmonds M.S.J. (2005) Ethnobotanical study of some Ghanian anti-malarial plants. Journal of Ethnopharmacol. 2005; 99: 273-279. 